\title{
International Liquidity Provision During the Financial Crisis: A View from Switzerland
}

\author{
Raphael Auer and Sébastien Kraenzlin
}

\begin{abstract}
The authors document the provision of liquidity in Swiss francs (CHF) by the Swiss National Bank (SNB) to banks located outside Switzerland during the recent financial crisis. What makes the Swiss case special is the size of this liquidity provision—at times, 80 percent of all short-term CHF liquidity provided by the SNB — and the measures adopted to distribute this liquidity. In addition to making CHF available to other central banks via swap facilities, the SNB also allows banks outside Switzerland to directly participate in its repurchase agreement transactions. Although this policy was adopted for reasons predating the 2007-09 financial crisis, it proved tremendously helpful during the crisis by providing the European banking system direct access to the primary funding facility for CHF. (JEL E41, E52, F33, F34)
\end{abstract}

Federal Reserve Bank of St Louis Review, November/December 2011, 93(6), pp. 409-17.

n the years leading up to 2007 , banks across the globe dramatically increased their balance sheet exposure to foreign currencies. This led to increased trading between banks with a need to refinance in the foreign currency and domestic banks with deposits and consequently sufficient funds to lend in that currency (i.e., extensive cross-border trading). With the onset of the financial crisis and the successive drying-up of the repurchase agreement (repo) market and especially the unsecured interbank money market (see Guggenheim, Kraenzlin, and Schumacher, 2011), the private sector no longer provided this liquidity, thus requiring a coordinated action by the world's major central banks.

In particular, the provision of dollar liquidity to non-U.S. banks by the Federal Reserve garnered ample attention in the global financial press (for a discussion, see, for example, Goldberg, Kennedy, and Miu, forthcoming). Much less noticed was the Swiss National Bank's (SNB) large-scale provision of Swiss franc (CHF) liquidity to the banking system throughout the European Union and beyond.

In this article, we document the CHF liquidity provision by the SNB to banks located outside Switzerland. What makes the Swiss case special is not only the size of the liquidity provision to banks outside Switzerland (at times, 80 percent of all short-term CHF liquidity provided by the $\mathrm{SNB}$ ), but also the measures adopted to distribute this liquidity.

In addition to providing $\mathrm{CHF}$ to other central banks via swap facilities, the SNB allows foreign banks to directly participate in its repo transactions. Although this policy was adopted for reasons predating the recent financial crisis, it proved

Raphael Auer is deputy head of the International Trade and Capital Flows Unit at the Swiss National Bank and a research associate at the Liechtenstein Institute on Self-Determination at Princeton University. Sébastien Kraenzlin is a senior economist at the Money Market and Foreign Exchange Division of the Swiss National Bank. The authors thank Jean-Pierre Danthine, Andreas M. Fischer, William T. Gavin, Andreas Ittner, Dewet Moser, Thomas Moser, Daniel L. Thornton, and another anonymous referee for comments and suggestions.

(C) 2011, The Federal Reserve Bank of St. Louis. The views expressed in this article are those of the author(s) and do not necessarily reflect the views of the Federal Reserve System, the Board of Governors, the regional Federal Reserve Banks, or the Swiss National Bank. Articles may be reprinted, reproduced, published, distributed, displayed, and transmitted in their entirety if copyright notice, author name(s), and full citation are included. Abstracts, synopses, and other derivative works may be made only with prior written permission of the Federal Reserve Bank of St. Louis. 
tremendously helpful during the crisis when it gave the European banking system direct access to the primary funding facility for CHF.

Finally, the Swiss case is exceptional because from March 2009 to June 2010, faced with deflation risks and zero interest rates, the SNB intervened in the foreign exchange market as part of its unconventional policies. The resulting largescale inflow of CHF to the financial sector flooded the international banking system with CHF liquidity. As a consequence, demand for the liquidity provided by the SNB's open market operations virtually ceased to exist. We believe that, although liquidity provision itself was not an objective of the foreign exchange interventions, the transactions may have contributed to stabilizing the European banking system.

\section{THE ORIGINS: SWISS FRANC LOANS IN AUSTRIA AND CENTRAL AND EASTERN EUROPE}

Because of the traditionally low interest rates in Switzerland and the low-exchange-rate volatility observed since the introduction of the euro (EUR), many households and firms across Central and Eastern Europe (CEE) relied on CHFdenominated loans as a source of cheap funding. The resulting aggregate exposure was substantial: By early 2009, households and non-bankingsector firms in CEE economies had accumulated the equivalent of CHF 120 billion worth of debt denominated in Swiss currency. In Austria, primarily because of its geographic proximity to Switzerland, total exposure was then over CHF 80 billion. Non-banks in the other countries of the euro zone also relied on such loans. In total, the exposure of non-Swiss European banks amounted to about CHF 400 billion in late 2008. ${ }^{1}$

1 Why lenders that issued these loans were not more concerned with the embedded default risk might seem puzzling. However, a microeconomic study of loan issuance to private households in Austria (see Beer, Ongena, and Peter, 2008) finds that banks did screen potential borrowers and awarded CHF-denominated loans only to the more solvent clients (also see Auer et al., 2009). In addition, many such loans contained provisions giving the banks the right to coerce conversion of a loan to the local currency if the exchange rate exceeded a certain trigger level. The combination of these two features probably explains why lenders were not concerned with default risk when issuing these loans.
The size of the exposure has raised many concerns about the financial stability of the banking sector, given the possibility of continued CHF strength or even appreciation. (Most notable are concerns expressed by Krugman, 2009.) Since few of the debtors have any CHF income, such an appreciation could cause large-scale default and the resulting loan losses could strain the banking sector in these economies. ${ }^{2}$ However, a second financial stability concern related to the CHF loans has received surprisingly little attentionwith the notable exception of Pann, Seliger, and Übeleis (2010)—namely, the resulting funding and liquidity risk faced by non-Swiss banks.

\section{SYSTEMIC SWISS FRANC SHORTAGES DURING THE CRISIS}

CHF-denominated loans obtained by nonbanks outside Switzerland are typically granted by non-Swiss banks that, in turn, finance themselves by borrowing from financial institutions in Switzerland. As in all bank business, these nonSwiss banks provide long-term loans yet finance themselves on a short-term basis. Their ability to roll over maturing CHF positions became stressed when the interbank money market progressively dried up following the onset of the financial crisis in August 2007, particularly after the collapse of Lehman Brothers in September 2008 (see Guggenheim, Kraenzlin, and Schumacher, 2011).

In international currency markets, any bank can potentially obtain financing in any foreign currency either by going directly to the interbank money market or by obtaining funds from its central bank and swapping the received funds into the desired foreign currency. In principle, these two methods should ensure the rate at which a currency is funded is the same.

During the recent financial crisis, however, interbank money markets temporarily faltered.

\footnotetext{
2 The aggregate exposure of CEE and Austria to low-interest-rate currencies had already caused losses of around $\$ 60$ billion (U.S. dollars) for these nations in 2008-09 alone; see Auer and Wehrmüller (2009). Note that empirical studies by Beer, Ongena, and Peter (2008); Brown, Ongena, and Yesin (2011); Brown, Peter, and Wehrmüller (2009); and Puhr, Schwaiger, and Sigmund (2009) show that the debtors tend to be creditworthy, thus suggesting that such concerns are less relevant than the sheer magnitude of the aggregate exposure suggests.
} 


\section{Figure 1}

\section{Difference Between Unsecured and Secured Overnight Interbank Rate for CHF Funds and EUR Funds}

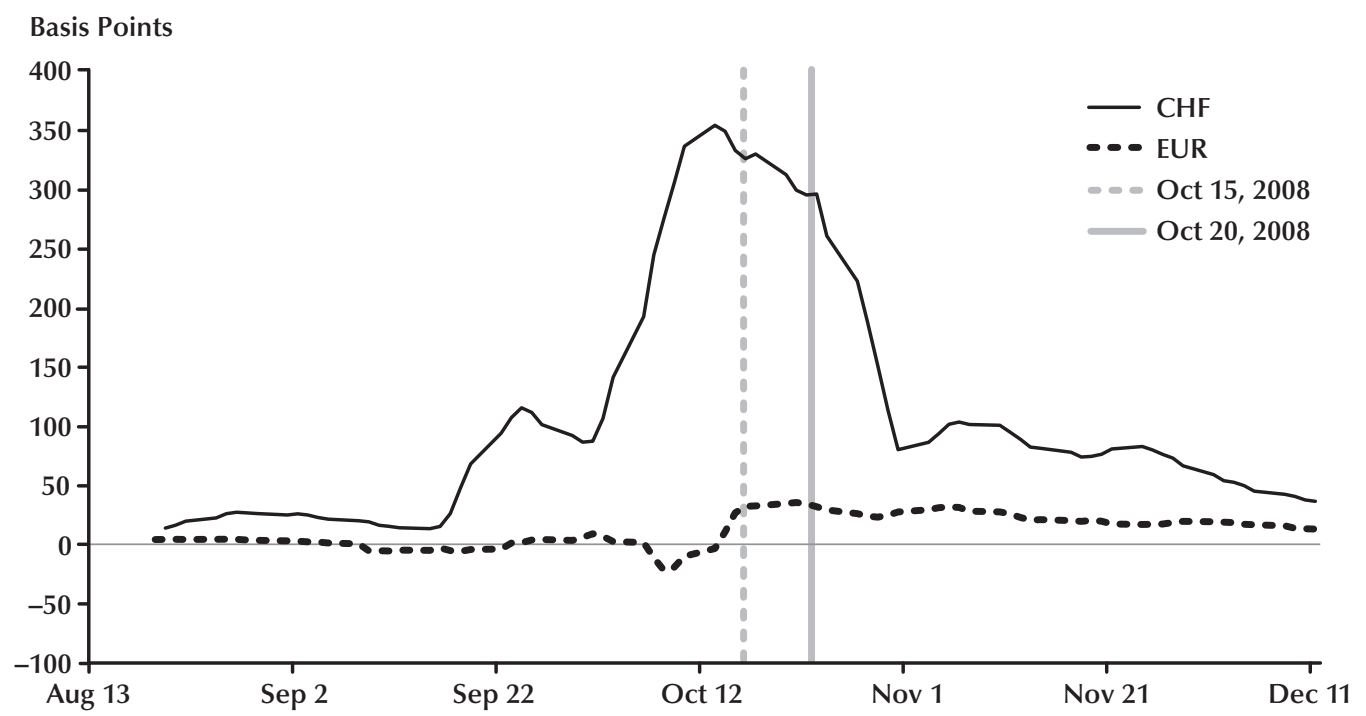

NOTE: The figure shows the evolution of the difference between the unsecured and secured overnight interbank rate for Swiss franc (CHF) funds and euro (EUR) funds from August to November 2008 (5-day moving average). The two horizontal lines correspond to the announcement (October 15, 2008) and the actual start (October 20, 2008) of EUR/CHF swap auctions by the European Central Bank, Magyar Nemzeti Bank (the central bank of Hungary), and the National Bank of Poland.

For example, Figure 1 documents the strains in the CHF money market beginning in October 2008. The figure plots the difference between the unsecured and secured overnight interbank rate for both CHF funds and EUR funds. While these two spreads are historically rather low and co-move closely, the spread on CHF rose steeply during October 2008, reaching values well over 300 basis points. Consequently, the movement in the CHF money market is a result of an increase in liquidity and not credit risk premia since the latter would be reflected in both currencies.

The CHF-specific spike in the cost of obtaining unsecured funds was caused by a combination of the need by banks outside Switzerland to continuously roll over maturing interbank loans and the shrinking supply for these funds. Most Swiss banks and a considerable number of non-Swiss banks have access to the Swiss repo system-the prevailing secured money market in Swiss francs. In a calm market environment, these banks would have immediately exploited this profit opportunity and provided unsecured funds to banks without access to the Swiss repo system.

However, against the backdrop of the global financial crisis and the fear of counterparty default risk, this situation did not occur and the spread between secured and unsecured CHF funds remained elevated for several trading days. Without access to the Swiss repo system, even banks with ample collateral could not obtain secured funding from the SNB or the secured interbank market. In Switzerland, only a negligible amount of repo transactions are traded outside the Swiss repo system (i.e., over the counter).

The lower cross-border trading could have posed a substantial danger to the stability of the financial sector at large. If banks across the euro zone and CEE were unable to obtain CHF in the money market, then non-Swiss banks, in turn, could try to reduce their exposure by liquidating CHF loans they had made to their clients. Given 


\section{Auer and Kraenzlin}

the banking tensions at the time, this move would have driven many debtors into default and could have started a disorderly winding-down of CHF loans, with increasing default rates implying the need for additional loan-loss provisions, thereby increasing pressure to liquidate CHF exposure. This vicious cycle could have had dire consequences for the banking system and the real economy.

\section{PHASE I: INTER-CENTRAL BANK SWAP FACILITIES}

The drying-up of liquidity distribution in foreign currency posed a problem more challenging than the breakdown of the domestic interbank money market: No central bank, on its own, can provide a large amount of liquidity in a foreign currency in a timely manner. ${ }^{3}$ First, the European Central Bank (ECB) and the central banks in CEE obviously cannot create CHF liquidity without issuing their own debt securities in the respective currency. Second, the SNB can create CHF liquidity but cannot supply this liquidity to banks lacking access to the Swiss repo system or banks with insufficient SNB-eligible collateral, which in 2007 was the case for most banks involved in CHFdenominated lending in CEE. 4

To overcome this market friction, the SNB jointly announced with the ECB and subsequently with the Narodowy Bank Polski (the National Bank of Poland) and the Magyar Nemzeti Bank (the central bank of the Republic of Hungary) that all these central banks would directly distribute CHF-denominated funds to their counterparties. ${ }^{5}$ Since (i) nearly all banks that require funding of some CHF exposure are registered with one of

\footnotetext{
3 The SNB also issued its own debt certificates in U.S. dollars (SNB USD bills). The U.S. dollars were subsequently used to finance the SNB's loan to its stabilization fund. The outstanding volume peaked at $\$ 20$ billion USD. A central bank can thus obtain foreign currency and subsequently provide liquidity to its counterparties. Depending on the urgency and extent of lending, however, it may prove difficult.

4 In general, the establishment of access to the Swiss repo system takes several months. Hence, banks with CHF exposure but no access to the Swiss repo system could not establish access quickly enough.
}

these four central banks and (ii) the conditions for these funds are similar across these countries, in effect the private sector instantly gained access to the primary source of CHF: the SNB. ${ }^{6}$

As Figure 1 clearly shows, on the value date of the first swap transaction, the CHF tensions in the unsecured money market ceased once the CHF auctions were implemented by the partner central banks. In other words, the swap transactions were effective in reducing the liquidity premium and in returning the interest rate spread for Swiss francs to a level similar to that for euro funds.

Figure 2 documents the extent to which banks located in the European Union used the EUR/CHF swap facility. With the introduction of the facility, demand for $\mathrm{CHF}$ in the euro zone jumped to around CHF 40 billion and stayed there for about 6 months. Thereafter, demand for Swiss francs under the EUR/CHF swap facility leveled off and ceased after January 2010.

\section{PHASE II: ENHANCING FOREIGN BANKS' DIRECT ACCESS TO THE REPO SYSTEM}

Figure 1 demonstrates that the EUR/CHF swap was a functioning measure to address short-run liquidity mismatches. Since swaps are just a means to distribute liquidity more effectively, they involve no direct costs, but they do still have limits. First, their maximum volume is agreed upon in advance, so they are not as flexible as measures controlled by only one central bank. Second, the swap agreement itself to some extent fractionalizes the market for CHF liquidity since

\footnotetext{
5 Although the central bank swap agreements are bilateral, it is sometimes the case that funding is "recycled" to other countries. This is an especially relevant channel for international CHF liquidity provision as it is likely that banks in the euro area, particularly Austrian banks, forwarded CHF funds to their subsidiaries across CEE. Thus, the CHF funding was indirectly available to more countries.

6 The Hungarian central bank offered slightly different conditions than the other central banks. See Goldberg, Kennedy, and Miu (2011), Auer and Kraenzlin (2009), and Aizenman and Pasricha (2010) for a discussion of various swap line agreements around the globe.
} 


\section{Figure 2}

\section{Volume of CHF Loans to Euro Zone Banks via the EUR/CHF Swap Facility}

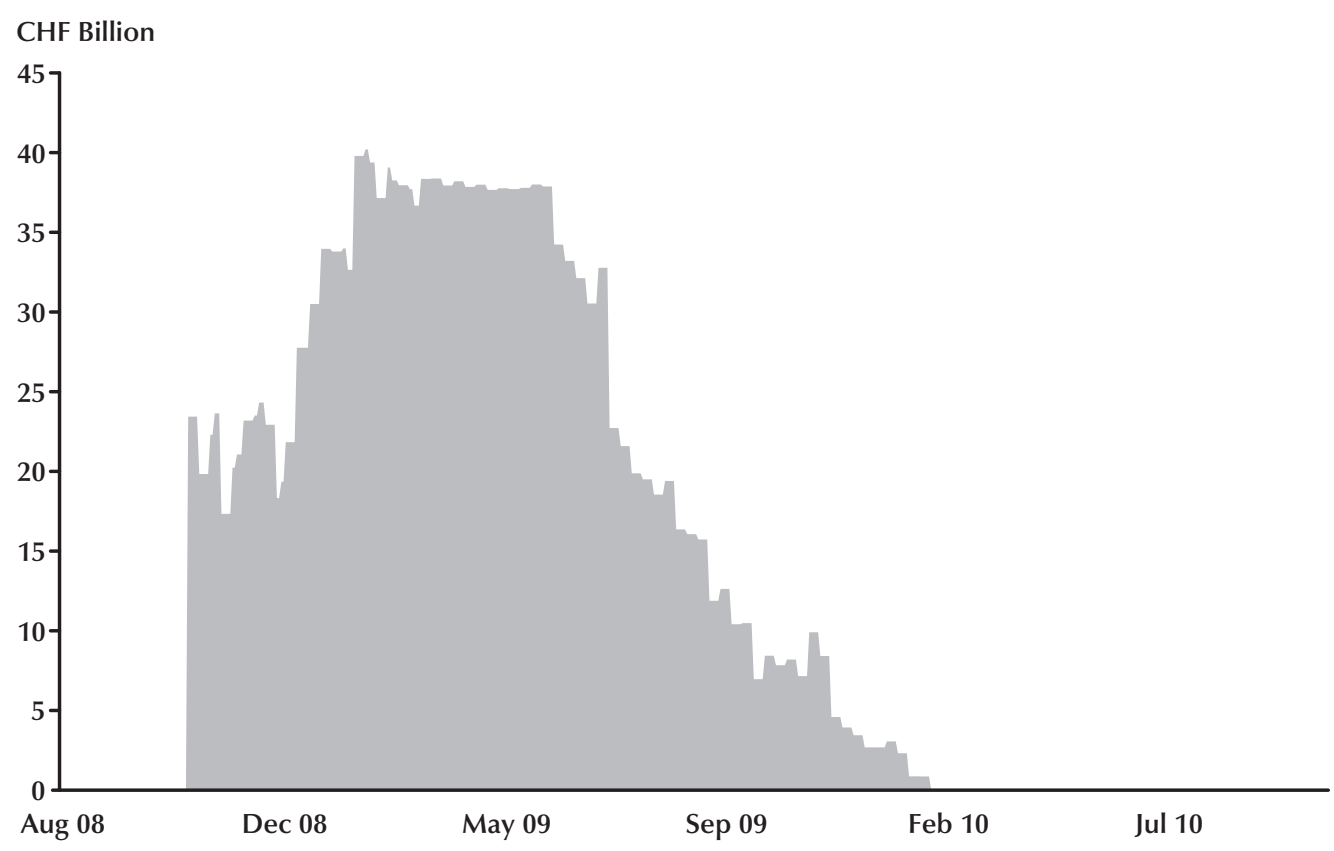

the total supply of CHF is split across different selling platforms. ${ }^{7}$

Finally, swap agreements also involve some loss of control over monetary policy because, in essence, the monetary base is partly controlled by a foreign central bank. The main worry of policymakers is that such swap agreements could create inflationary pressure because opening new means to distribute liquidity can increase the total supply of money. For example, the maximum amount of a swap is agreed upon months in advance. Since the receiving central bank may auction off the maximum amount (but is not obliged to do so), uncertainty in the growth of the money supply is increased. ${ }^{8}$ Given these shortcomings, the $\mathrm{SNB}$, the ECB, and the euro zone member central

7 A further potential worry is that these agreements could entail a larger counterparty default risk. This is not the case. First, there is no risk involved for the central bank distributing the funds since the receiving central banks guarantee these transactions. Second, there is also no effect on counterparty default risk for the receiving central bank since it transacts with its regular counterparties against the regular collateral basket. banks, as well as all other affected central banks, advised banks with major exposure to the CHF to seek access to the SNB's repo system. ${ }^{9}$

The SNB is also legally empowered to provide liquidity to banks outside Switzerland. ${ }^{10}$ The original intent in allowing foreign banks to access the Swiss repo system was to (i) reduce

8 Two main reasons explain why the loss of control of the monetary base is rather contained. First, the central bank that originates the funds can sterilize the effect on the monetary base by issuing its own debt certificates or providing liquidity, thereby absorbing open market operations. While ceding some control over monetary policy to other central banks is of little concern in the current low-inflation environment, such concerns will definitely become a first-order political topic once inflationary pressures resume and central banks must refocus on their core task of maintaining price stability.

9 In particular, the Austrian financial authorities (the Austrian National Bank and the Austrian Financial Market Authority [Finanzmarktaufsicht]) have assumed a key role in persuading commercial banks in Austria to seek access to the Swiss repo system.

10 The repo system used by the SNB is also the same system in which the majority of interbank $\mathrm{CHF}$ repo transactions are conducted. Hence, even banks without access to the SNB could use the interbank repo market for refinancing purposes. 
Figure 3

\section{Use of the SNB Repo System by Banks Within and Outside Switzerland}

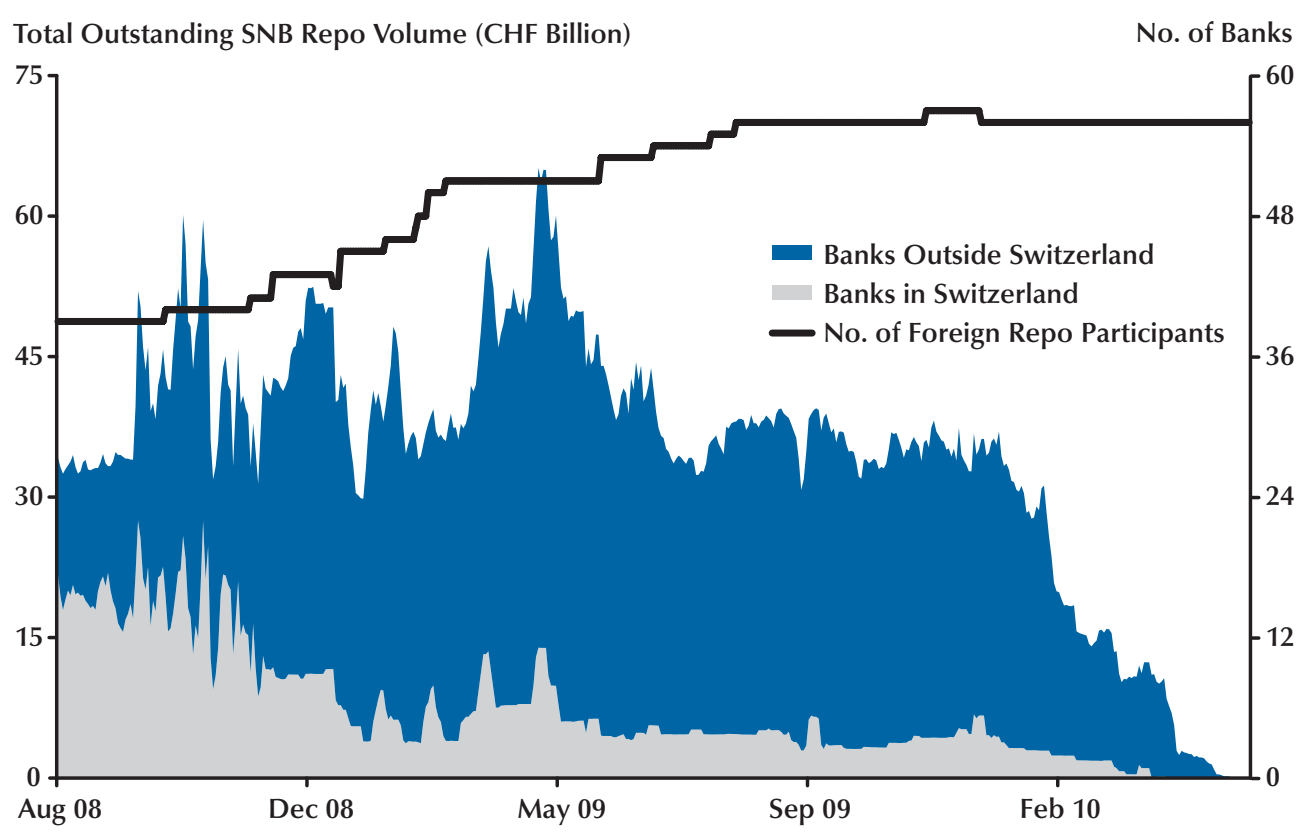

the dependence on the few large Swiss financial institutions, (ii) improve the general liquidity in the banking system, and (iii) thereby facilitate the steering of a longer-term money market ratenamely, the 3-month CHF London Interbank overnight rate (LIBOR).

This pre-crisis policy also proved useful in addressing cross-border liquidity shortages during the financial turmoil. The solid black line in Figure 3 plots the evolution of the number of banks in the Swiss repo system located outside Switzerland (right axis). As of mid-November 2010, 59 such banks had established access to the Eurex Repo electronic trading platform, a necessary condition to participate in the SNB's repo auctions. Of these 59 banks, 23 were located in Austria, 16 in Germany, and 6 in the United Kingdom. ${ }^{11}$

Figure 3 also documents the volume of CHF liquidity obtained directly from the SNB by foreign banks, which temporarily exceeded CHF 60 billion. The comparatively small volume of $\mathrm{CHF}$ liquidity obtained by Swiss banks makes clear just how sizable the foreign demand was: For most of 2009 and early in 2010, well over 70 percent of the liquidity demand was from outside Switzerland. With the money obtained indirectly through EUR/CHF swaps, short-term CHF liquidity held by non-Swiss Banks rose to 90 percent.

Figure 4 highlights the importance of direct access to the SNB repo system for banks located outside Switzerland (see also Kraenzlin and von Scarpatetti, 2011). This figure presents an area diagram (stacked) showing total provision of CHF liquidity to banks located outside Switzerland. The figure shows the volume supplied within the Swiss repo system (light blue) and the volume supplied via EUR/CHF swaps (dark blue).

\footnotetext{
${ }^{11}$ The SNB also accepts securities denominated in foreign currency. High credit standards and a highly efficient risk management procedure imply that the SNB does not apply haircuts. Banks located outside Switzerland thus can deliver non-CHF-denominated securities in SNB repo transactions. It is unclear to what extent this possibility has contributed to the high use of the SNB repo facility by this group of banks observed during 2009 and early 2010 .
} 


\section{Figure 4}

\section{Total Liquidity Provision to Banks Outside Switzerland}

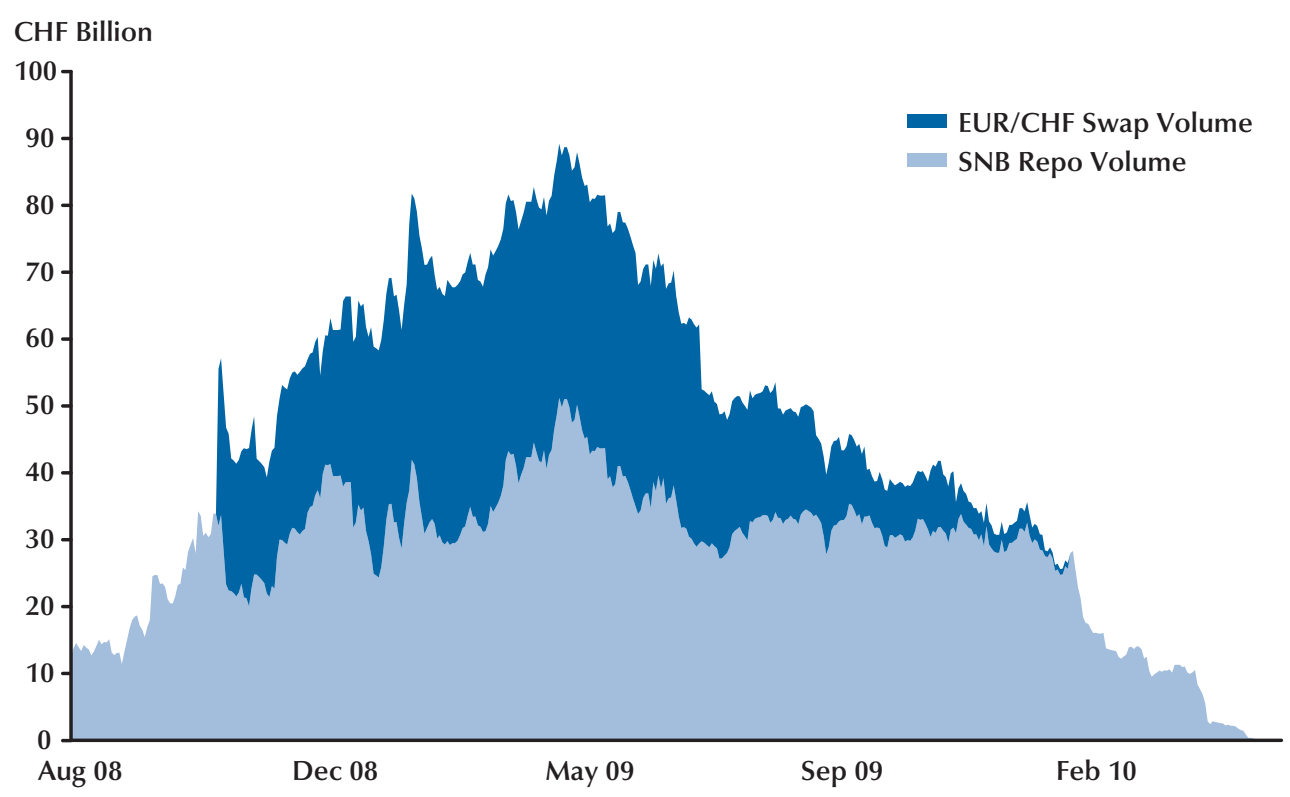

\section{PHASE III: EXCHANGE RATE INTERVENTIONS}

Figures 3 and 4 document not only the extent of the CHF shortage during 2008 and 2009, but also that this demand decreased substantially starting in mid-2009; demand vanished completely in mid-2010. Although it is tempting to attribute this to a resurgence of activity in the interbank money market, this is not fully the case. Rather, starting in March 2009, the SNB intervened in the foreign exchange market, eventually building up a foreign reserve position worth over CHF 200 billion, compared with a pre-2009 level of less than CHF 50 billion.

While the exchange rate interventions were part of the SNB's unconventional measures to avert deflation risks in Switzerland, an unintended side effect of the interventions was the resolution of the international CHF liquidity shortage: The supply of the additional CHF 150 billion is available to the banking system on a permanent basis and, consequently, the majority of banks are awash with CHF liquidity.
Figure 5 puts the extent of the liquidity provision via the exchange rate interventions in perspective. The figure shows the combined total of CHF liquidity supplied to banks located within and outside Switzerland. The three key elements of this supply are the Swiss repo system (dark gray area), the EUR/CHF swaps (light gray area), and the SNB exchange rate interventions (black area).

Figure 5 documents that the exchange rate interventions were so sizable that they in effect created enough liquidity that demand for liquidity via repo and swap transactions ceased altogether. In fact, the SNB currently absorbs liquidity to implement monetary policy. This is done, on the one hand, through weekly issuance of the SNB's own money market bills (SNB bills) and, on the other hand, through daily one-week repo auctions (see also Anderson, Gascon, and Liu, 2010, and SNB, 2011).

The exchange rate interventions thus proved helpful from a financial stability perspective. Using loans denominated in a low-interest-rate currency such as the CHF is essentially a carry 


\section{Figure 5}

\section{Total Supply of CHF Liquidity}

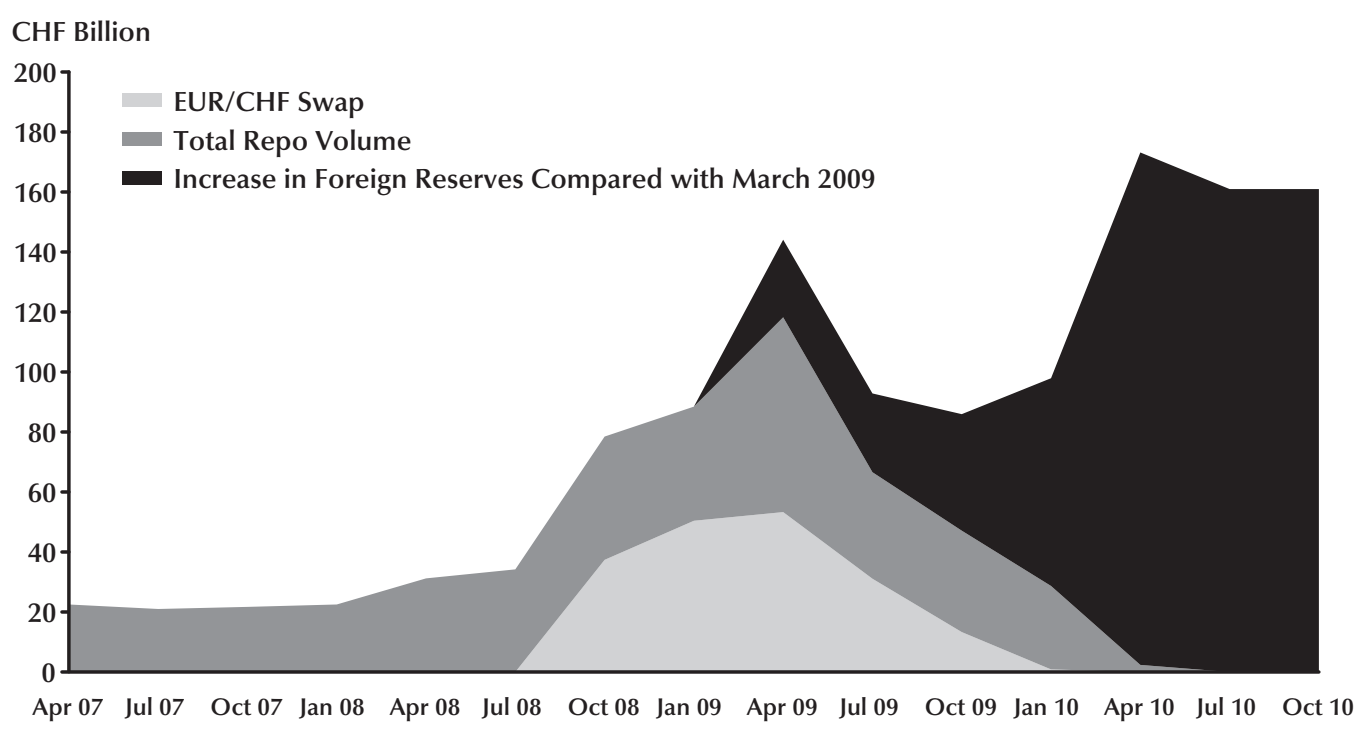

SOURCE: Data for reserve levels are from the SNB's Monthly Statistical Bulletin.

trade strategy. Such strategies are always subject to the danger of a disorderly winding-down of positions: If the losses stemming from an appreciation of the CHF become too large such that counterparty default risks surface, carry traders can no longer refinance their positions and must liquidate them; this, in turn, causes a further appreciation of the CHF. The combination of swap facilities, enhanced direct access to the primary source of CHF liquidity, and exchange rate interventions was instrumental in ensuring that, to date, such sizable disruptive winding-downs have not taken place and are unlikely in the near future.

\section{CONCLUSION}

Small frictions in how the private sector distributes liquidity internationally can have large effects on the interest rate paid. The rapid, coordinated, and large policy response by central banks across Europe may have avoided a disorderly winding-down of the carry trade positions built up by European households and firms in the years leading up to the recent financial crisis.

International liquidity mismatches involving Swiss francs are currently of little concern, which may be an unintended side effect of the liquidity injection via SNB interventions in the foreign exchange market. The establishment of access to the Swiss repo system by banks outside Switzerland also contributed to this relatively calm environment. As of this writing, the private sector thus has won time to reduce its CHF exposure in an orderly way. 


\section{REFERENCES}

Aizenman, Joshua and Pasricha, Gurnain Kaur. "Selective Swap Arrangements and the Global Financial Crisis: Analysis and Interpretation." International Review of Economics and Finance, June 2010, 19(3), pp. 353-65.

Anderson Richard G.; Gascon, Charles S. and Liu, Yang. "Doubling Your Monetary Base and Surviving: Some International Experience.” Federal Reserve Bank of St. Louis Review, November/December 2010, 92(6), pp. 481-505; http://research.stlouisfed.org/publications/review/article/8509.

Auer, Raphael A.; Brown, Martin; Fischer, Andreas M. and Peter, Marcel. "Will the Crisis Wipe Out Small Carry Traders in Central and Eastern Europe?” VoxEU.org, January 29, 2009; www.voxeu.com/index.php?q=node/2916.

Auer, Raphael A. and Kraenzlin, Sébastien P. "The Effectiveness of Central Bank Swap Agreement as a CrisisFighting Tool.” VoxEU.org, October 14, 2009; www.voxeu.org/index.php?q=node/4084.

Auer, Raphael and Wehrmüller, Simon. "How Big Are the Eastern European Losses?” VoxEU.org, April 20, 2009; www.voxeu.org/index.php?q=node/3467.

Beer, Christian; Ongena, Steven R.G. and Peter, Marcel. "Borrowing in Foreign Currency: Austrian Households as Carry Traders.” Journal of Banking and Finance, September 2010, 34(9), pp. 2198-211.

Brown, Martin; Ongena, Steven R.G. and Yesin, Pinar. "Foreign Currency Borrowing by Small Firms in the Transition Economies.” Journal of Financial Intermediation, July 2011, 20(3), pp. 285-302.

Brown, Martin; Peter, Marcel and Wehrmüller, Simon. "Swiss Bank Lending in Europe.” Policy paper, Swiss National Bank, February 2009; www.snb.ch/n/mmr/reference/sem 20080922 background/source.

Goldberg, Linda S.; Kennedy, Craig and Miu, Jason. "Central Bank Dollar Swap Lines and Overseas Dollar Funding Costs.” Federal Reserve Bank of New York Economic Policy Review, May 2011; www.newyorkfed.org/research/epr/11v17n1/1105gold.pdf.

Guggenheim, Basil; Kraenzlin, Sébastien P. and Schumacher, Silvio. "Exploring an Uncharted Market: Evidence on the Unsecured Swiss Franc Money Market.” Working Paper No. 2011-5, Swiss National Bank, 2011; www.snb.ch/n/mmr/reference/working_paper 2011 05/source/working_paper 2011 05.n.pdf.

Kraenzlin, Sébastien P. and von Scarpatetti, Benedikt. "Liaisons and Scheming: The Network of the Swiss Franc Repo Market.” Swiss National Bank working paper (forthcoming).

Krugman, Paul R. “The Conscience of a Liberal: Austria.” New York Times, April 15 2009; http://krugman.blogs.nytimes.com/2009/04/15/austria/.

Pann, Johannes; Seliger, Reinhardt and Übeleis, Julia. "Foreign Currency Lending in Central, Eastern and Southeastern Europe: The Case of Austrian Banks.” Financial Stability Report 20. Austrian National Bank, December 2010, pp. 56-76; www.oenb.at/en/img/fsr 20 gesamt tcm16-214505.pdf.

Puhr, Claus; Schwaiger, Markus S. and Sigmund, Michael. "Direct Cross-Border Lending by Austrian Banks to Eastern Europe.” Financial Stability Report 17. Austrian National Bank, June 2009, pp. 102-22; www.oenb.at/en/img/fsr 17 gesamt tcm16-140492.pdf.

Swiss National Bank. Swiss National Bank: 103rd Annual Report 2010. Zurich: SNB, 2011; www.snb.ch/en/mmr/reference/annrep $2010 \mathrm{komplett/source.}$ 
